\title{
Reinforcement of RC structure by carbon fibers
}

\author{
B. Kissi ${ }^{1}$, Y. Riyad ${ }^{2}$, I. Mrani ${ }^{2}$, B. EL Ghoulbzouri ${ }^{3}$, M.A. Parron ${ }^{4}$, and Y. El khatib ${ }^{1}$ \\ ${ }^{1}$ University Hassan II, ENSAM Casablanca, Morocco \\ ${ }^{2}$ University Chouaib Doukkali, FS El-jadida, Morocco \\ ${ }^{3}$ National School of Applied Sciences of Al Houceima, Morocco \\ ${ }^{4}$ University of Cadiz, Ramon Pujolavenue, Algeciras 11202, Spain
}

\begin{abstract}
In recent years, rehabilitation has been the subject of extensive research due to the increased spending on building maintenance work and restoration of built works. In all cases, it is essential to carry out methods of reinforcement or maintenance of structural elements, following an inspection analysis and methodology of a correct diagnosis. This research focuses on the calculation of the necessary reinforcement sections of carbon fiber for structural elements with reinforced concrete in order to improve their load bearing capacity and rigidity. The different results obtained reveal a considerable gain in resistance and deformation capacity of reinforced sections without significant increase in the weight of the rehabilitated elements.
\end{abstract}

\section{Introduction}

The disorders occurring in structures are often due to the degradation of the materials used, or the change in the load of the structure (excess load). The deterioration of materials (including reinforced concrete) over time, or the structural modification of buildings spur the development of efficient technologies of reinforcement.

The overriding criteria in the evaluation of these technologies are the sustainability of the technology solution and the lowering of the implementation constraints [1].

The method which has emerged in recent years is the reinforcement by composite materials [2]. This method uses the bonding of composite plates (Textile unidirectional or bidirectional reinforcement, strips, carbon fibers...) or in situ direct lamination of composites (textile fabrics, glass or carbon) associated to thermosetting polymer matrices (epoxy resins, polyester ...).

This technique of reinforcement is an innovative alternative to the traditional solution using bonding metal plates. Its use is relatively recent. It dates back to about a decade in Civil Engineering [3].It began to be marketed in the 1980s in the United States, Japan and Europe. The development of this technology in the USA and Europe is due to the need of reinforcing the aged structures or the ones which their functionality has changed.

The reinforcement of beams can occur in two ways [4]; the first way is the resumption of flexural strains; two reinforcing techniques are used to take up the bending efforts: the bonding plates or bonding strips.

Gluing plates on strained concrete areas is the oldest methods, it suffers from a big disadvantage: its lack of adaptability. It presents a difficulty of implementation, in fact the adhesion between the plate and the reinforced element must coincide perfectly.

The bonding of strips technique appeared in 1980. It is similar to the other method, the only difference is that the bonded element is adjustable to the reinforced structure.

The second way is the resumption of shear strains; it is done using reinforcements arranged transversely to the axis of the beam to strengthen the transverse reinforcement.

Again, the reinforcements may be in the form of strips or plates but the predominant method is the bonding strips. FRP (fiber reinforced polymer) consists of fibers arranged in one direction. Care should be taken to place the reinforcements in the right direction to take up the forces.

There are three different arrangements of reinforcements for taking up the shear efforts of a beam [5]: The bonding of reinforcement on the four faces of the beam (a), the bonding of reinforcement on the three sides of the beam as " $U$ " (b), the bonding of reinforcement on both sides of the beam web (c). 


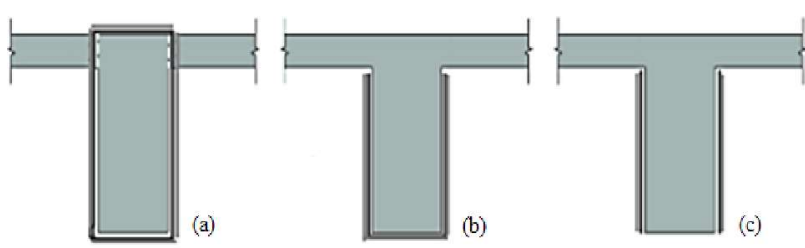

Fig. 1. Disposition of reinforcement strips on the beam (FRP shear reinforcement)

For the reinforcement of columns, the first studies began after the Loma Prieta earthquake in San Francisco bay, California at 1989. The first publications on this subject come from (CHAI and al 1991. Priestley and al.1992). This type of reinforcement is obtained by confining the reinforced concrete members with CFRP strips. When the reinforcement is applied around a column; its compressive strength and ductility are improved. The improvement of compressive strength of concrete appears only after the appearance of cracks and the beginning of the expansion. In this case, the CFRP wrap allow to the column to take up an additional compressive forces.

When the reinforcement is applied around a column, its compressive strength and ductility are improved. The improvement of compressive strength of concrete appears only after the appearance of cracks and the beginning of the expansion. In this case the FRP wrap allow to the column to take up an additional compressive forces.

When an axial load is applied to the column, the concrete expands laterally, in particular due to the Poisson effect, creating tensile stresses in the reinforcement, which opposes the increase in section. The reinforcing wrap confines then the section of the column. The result is an increase of the bearing capacity and ductility of structure.

The functioning of the reinforcement of this type of elements is different from the reinforcement of horizontal elements such as slabs or beams. In fact, for slabs and beams, reinforcements must increase the properties already provided by the frames. The properties of steel and concrete are not changed. In the case of reinforcement of the columns, the reinforcements make change the apparent characteristics of the concrete.

To increase the compression resistance for the elements, FRP strips are used in the same direction of the frames. There are three methods for the application of strips [4]: The reinforcement of a full post (a), the partial reinforcement with continuous spiral winding (b), and the partial reinforcement by rolling rings (c)

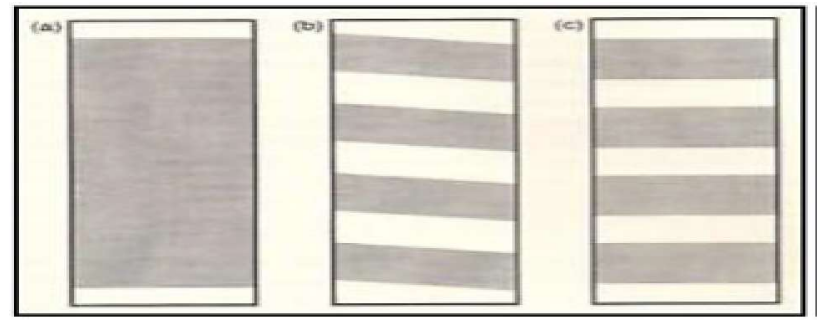

Fig. 2. Different type of reinforcements disposition on a column [4]

\section{Equation of the problem}

\subsection{Vertical elements}

The method we will follow to design the necessary reinforcement is as follows: [6]

- Determination of the nominal and factored capacities of the existing column. :

$$
\begin{aligned}
& \phi P_{n(\max )}=\phi \times 0.85 \times\left(0.85 \times{f^{\prime}}^{\prime} \times\left(A_{g}-A_{s t}\right)+\right. \\
& \left.f_{y} \times A_{s t}\right)
\end{aligned}
$$

where: $\mathrm{f}_{\mathrm{c}}{ }_{\mathrm{c}}$ : compressive strength of the concrete, $\mathrm{A}_{\mathrm{g}}$ : column section, $A_{\text {st }}$ : steel section, $f_{y}$ : yield strength of steel, $\Phi$ : strength resistance factor

- Determine the amount of strengthening required. :

Formula (2) gives the new loading of the column according to the live load $(\mathrm{G})$ and the dead load $(\mathrm{Q})$ :

$P_{u}=1,4 \times G+1,7 \times Q$

To determine the new load to be carried by the column we use the formula (3):

$P_{n}^{\text {requis }}=\frac{P_{u}}{\phi}$

We determine the required confined concrete compressive strength $\mathrm{f}_{\text {cc }}$ :

$f^{\prime}{ }_{c c}=\frac{\left(\frac{P_{n}^{\text {requis }}}{0.85}\right)-f_{y} \times A_{s t}}{\phi \times \psi_{f} \times\left(A_{g}-A_{s t}\right)}$

The required confining pressure $f_{l}$ is determined from the quadratic equation:

$f_{l}^{2} \times \frac{4}{\left(f^{\prime} c\right)^{2}}+f_{l} \frac{4 \times\left(\frac{f^{\prime} c c}{f^{\prime} c}+1.25\right)-40}{f^{\prime} c}+\left(\frac{f^{\prime} c c}{f^{\prime} c}+1.25\right)^{2}=0$

Finally, we calculate the necessary number of reinforcement layers:

$n=\frac{f_{l} \times D}{2 \times t_{f} E_{f} \varepsilon_{f e}}$

For a rectangular column, D is given by Lam and Teng's model [8]:

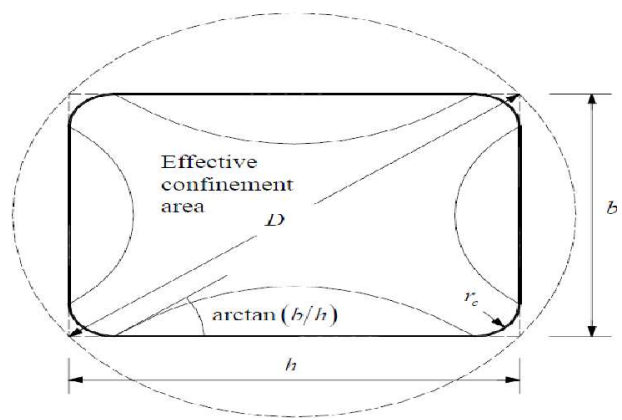

Fig. 3. Lam and Teng's model for FRP -confined concrete in rectangular columns [7] 


\subsection{Horizontal elements}

By knowing the efforts applied to the studied element (beam, slab), we can calculate the strains in concrete and frames and finally determine the required reinforcement section [6]:

Based on the balance equation, we determine the necessary section of reinforcement using the equation (18):

$A_{f}=\frac{\frac{M_{d}}{\phi}-A_{s} \times f_{y d} \times(d-0.4 \times x)}{\sigma_{f} \times \psi_{f} \times(h-0.4 \times x)}$

where: $\Psi_{\mathrm{f}}$ : strength reduction factor, $\Phi$ : resistance factor, $\sigma_{\mathrm{f}}$ : Stress in the reinforcements, $\mathrm{x}$ : position of the neutral axis, $A_{s}$ : steel section, $M_{d}$ : flexural Moment, $f_{y} d$ : yield strength of steel

\section{Result and discussion}

The aim of the study is to design a reinforcement of a beam in the first floor of a structure (this structure is a villa with an area of $386 \mathrm{~m}^{2}$ ). The table below summarizes the data of this beam:

Table 1. Beams data, load details, and material properties

\begin{tabular}{|c|c|c|c|c|c|}
\hline $\begin{array}{c}\text { Length } \\
(\mathrm{m})\end{array}$ & 3.78 & $\begin{array}{c}\text { Live } \\
\text { Load }(\mathrm{t} / \mathrm{m})\end{array}$ & 1 & $\begin{array}{c}\text { Concrete } \\
\text { compressive } \\
\text { strength }(\mathrm{MPa})\end{array}$ & 500 \\
\hline $\begin{array}{c}\text { Width } \\
(\mathrm{cm})\end{array}$ & 25 & $\begin{array}{c}\text { Dead } \\
\text { Load }(\mathrm{t} / \mathrm{m})\end{array}$ & 0 & $\begin{array}{c}\text { Yield } \\
\text { strength(MPa) }\end{array}$ & 25 \\
\hline $\begin{array}{c}\text { Height } \\
(\mathrm{cm})\end{array}$ & 25 & $\begin{array}{c}\text { Load at } \\
\text { ULS }(\mathrm{t} / \mathrm{m})\end{array}$ & 1.35 & $\begin{array}{c}\text { Steel section } \\
\left(\mathrm{cm}^{2}\right)\end{array}$ & 2.50 \\
\hline
\end{tabular}

The table 2 summarizes the results for a load increase ranging from $10 \%$ to $70 \%$ :

Table 2. Table showing the various parameters calculated based on load increase

\begin{tabular}{|c|c|c|c|c|c|c|c|}
\hline $\begin{array}{c}\text { Load } \\
\text { increase }\end{array}$ & $\mathbf{1 0 \%}$ & $\mathbf{2 0 \%}$ & $\mathbf{3 0 \%}$ & $\mathbf{4 0 \%}$ & $\mathbf{5 0 \%}$ & $\mathbf{6 0 \%}$ & $\mathbf{7 0 \%}$ \\
\hline $\begin{array}{c}\text { Load at } \\
\text { ULS } \\
(\mathbf{t} / \boldsymbol{m})\end{array}$ & 1.48 & 1.62 & 1.75 & 1.89 & 2.02 & 2.16 & 2.29 \\
\hline $\begin{array}{c}\text { Flexural } \\
\text { moment } \\
(\text { t.m })\end{array}$ & 2.65 & 2.89 & 3.13 & 3.38 & 3.62 & 3.86 & 4.10 \\
\hline $\begin{array}{c}\text { Reinforce } \\
\text { ment } \\
\text { section } \\
\left(\mathbf{c m}^{2}\right)\end{array}$ & 0.18 & 0.40 & 0.70 & 1.09 & 1.61 & 2.72 & 4.09 \\
\hline
\end{tabular}

Based on the table above, we established a curve representing the variation of the load based on the reinforcement section, as you can see in the figure below:

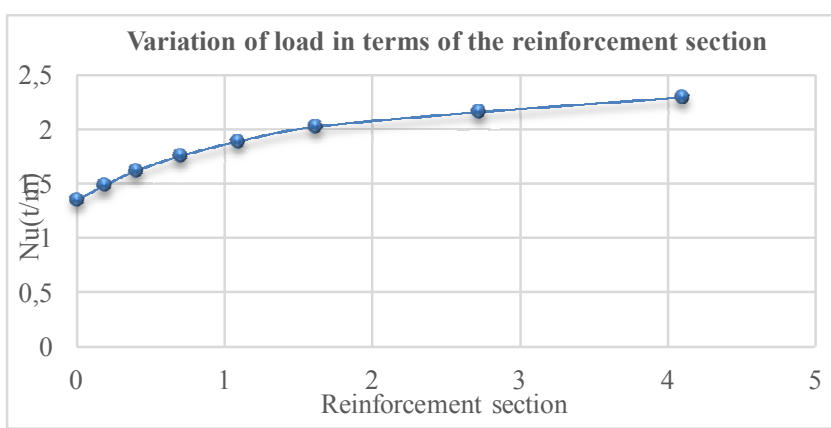

Fig. 4. Curve of the variation loads in terms of the reinforcement section

From the graph above, we can see that by using the same section of reinforced concrete and increasing the reinforcement section (section of CFRP), the beam could support a load that exceeds $70 \%$ of the load on which it was dimensioned . This proves that the reinforcement by carbon fiber is the most suitable solution to strength the structures having changed functionality or the aging structures. (A good ration weight/resistance, its resistance to fatigue, corrosion or even fire resistance).

\section{Conclusion}

The results obtained in this study are very encouraging; reinforcement by Carbon Fiber-Reinforced Polymer (CFRP) shows a part of its efficiency and leads to optimally reinforced structure. Depending on the type of stress, we now know the areas requiring reinforcement and the disposition of this latter.

However, the project we had the chance to conduct requires far more in-depth analysis.

In an additional study, it would be interesting to develop other methods and calculation models of reinforcement sections so that they can adapt to different types of sections.

\section{References}

1. H. Belhannachi, Rehabilitation et renforcement des poteaux en beton arme. $\mathrm{PhD}$, Mentouri-Constantine University, (2009) - p: 14\&15.

2. J. Miranda Vizuete, techniques et systemes de renfort des structures en beton, (2000) - p: 1.

3. A. Kassoul, rehabilitations des constructions en beton arme, Chapitre III - p: 17.

4. J. G. Teng, J. F. Chen, S. T. Smith, L. Lam; FRP: Strengthened RC Structures, Wiley, (2002).

5. A. Cecília, R.P. Ferreira, J. Cunha, Analysis of the distribution of reinforcement with carbon fibers in concrete beams, (2013) - Ciência \& Engenharia (Science \& Engineering Journal), ISSN 1983-4071 22 (2): p. $47-56$.

6. L.C. Bank, Composites for construction - Structural Design with FRP Materials- John Wiley \& Sons, (2006) - p: 324-333.

7. T. Jiang, FRP-Confined reinforced concrete columns: Analysis, behavior and design. $\mathrm{PhD}$, the Hong Kong Polytechnic University, July (2008) - p: 39. 